\title{
Alteridade e Educação em Levinas
}

\author{
Otherness and education in Levinas
}

José Tadeu Batista de Souza *

\begin{abstract}
Resumo
$O$ texto tem o objetivo de apresentar a categoria de subjetividade e seus modos de expressão no pensamento de Levinas, como inspiração para o ensino de Filosofia. Seu pensamento emerge tendo como novidade fundamental a alteridade, que marca toda sua obra. Sua crítica ao pensamento ocidental reclama o fato de ele ter negado a significação do outro. Levinas constatou que os esforços da razão ocidental em explicitar as problemáticas questões do ser, os modos de conhecimentos possíveis e as formas de agir constituíram-se na própria identidade da Filosofia. A identificação entre pensamento e ser tornou o pensar incapaz de abrir-se para a alteridade. Assim, o pensamento atuou como um movimento circular, reduzindo o que era diferente à mesmidade. Ao primado da identidade do mesmo Levinas propõe uma transformação para o fazer filosófico, que atinge tanto os conteúdos nucleares e os métodos da Filosofia, como a sua perspectiva mais geral. No que concerne aos conteúdos, ele propõe a "ética como filosofia primeira". A dimensão ontológica centrada no ser cede lugar ao humano como locus originário da busca da inteligibilidade e do sentido. $O$ humano perde o caráter de objeto de investigação teórica e sujeito cognoscente e torna-se polo de uma relação intersubjetiva fundada no diálogo aberto e no respeito incondicional à diferença do outro. A subjetividade plasma-se como instância fundamentalmente ética e pode expressar-se no desejo desinteressado pelo outro; na responsabilidade por ele e tem como medida a desmedida do infinito; na escuta paciente de quem reconhece no falante uma autoridade ensinante; na hospitalidade, como aquele que se alegra pela visitação desarranjadora do visitante inusitado; no encontro face a face com o rosto de outrem que traz uma significação
\end{abstract}

Doutor em Filosofia pela Pontifícia Universidade Católica do Rio Grande do Sul - PUCRS, Professor Adjunto III da Universidade Católica de Pernambuco - UNICAP, líder do Grupo de pesquisa Ética e Linguagem na Filosofia Contemporânea, linha de pesquisa Éticas da alteridade. em@il: jtadeuoli@hotmail.com 
originária e originante de novos sentidos: dizer de aprendizes e ensinantes.

Palavras-chaves: Levinas, subjetividade, alteridade, educação.

Abstract

The text aims to present the category of subjectivity and its modes of expression in the thought of Levinas, as inspiration for teaching philosophy. His thinking emerges on this as having novelty fundamental otherness, which marks all his work. His critique of western thought complains that he denied the significance of the other. Levinas found that the efforts of western reason in explaining the problematic issues of being, the modes of possible knowledge and the ways to act constituted the very identity of Philosophy. The identification between thought and being became thinking incapable to open to otherness. So thought served as a circular motion, reducing what was different to sameness. At the primacy of identity of the same, Levinas proposes a transformation to make philosophical, reaching both core content and methods of philosophy, as his more general perspective. Regarding the contents, he proposes "ethics as first philosophy." The ontological dimension centered on the being gives way to humans as locus originating in search of intelligibility and sense. The human loses the character of object of theoretical research and knowing subject and becomes the polo of a intersubjective relationship based on open dialogue and the unconditional respect for the other's difference. The subjectivity plasma itself as ethical fundamentally instance and can be expressed in the disinterested desire for another, in the responsibility for he and has as a measure the disproportionate of infinity; patient listening of who recognize in the speaker an authority teaching; hospitality, as that who rejoices by visitation disarray of visitor unusual; in meeting face to face with the face of others that brings originary meaning and originator of new meanings: tell learners and teachers.

Keywords: Levinas, subjectivity, otherness, education.

\section{Introdução}

\section{O texto a seguir tem como objetivo principal apresentar a compreensão levinasiana de Subjetividade. Pretende-se com}


isso mostrar que o entendimento da subjetividade pode constituir-se numa perspectiva de possíveis contribuições para o exercício do filosofar e de práticas pedagógicas. É óbvio que Levinas não foi um pensador especializado em educação. $\mathrm{Na}$ sua obra, não consta nenhum tratado de pedagogia ou didática. No entanto, é necessário afirmar-se que a educação não ficou excluída de suas reflexões. Como um judeu fiel às suas tradições, ele fez reflexões pontuais sobre a educação judaica. Em uma de suas obras, Dificil Liberdade: ensaios sobre o judaísmo, pode-se perceber três pequenos textos que versam particularmente sobre a educação. Eles aparecem no seguinte registro: "Reflexões sobre a educação judia"; "Educação e Oração" e "Anti-humanismo e Educação".

Mesmo sendo uma meditação circunscrita numa vertente religiosa, podem-se identificar intuições que são válidas e que podem ser apropriadas por qualquer tradição cultural. Particularmente, o texto "Anti-humanismo e Educação", publicado em 1973, apresenta perspectivas abertas à inspiração educacional, à prática política e à vivências éticas humanizantes. É provável que o autor tenha a intenção de nos fazer rememorar os tempos em que o homem ocidental teve a pretensão de procurar no humanismo a "sua razão de ser". A educação já foi pensada e pretendida como a instância guardadora, criadora e reprodutora do humanismo. $\mathrm{O}$ desenvolvimento das habilidades intelectuais no campo das Ciências, a criatividade nas dimensões das Artes, a busca de satisfações e do prazer de viver o cotidiano, o dimensionar as relações dos Estados com os outros na construção da paz já foram fundados em princípios humanistas. Lembrar essas habilidades encarnadas no tempo e no espaço histórico, talvez nos ajude a reagir diante de um "humanismo esquecido na retórica e na ideologia". Resgatar, portanto, a educação humanista para além de formulações teóricas, ainda que logicamente coerentes, poderá fazer do humano algo distinto das essências abstratas e dos conceitos fundados no anonimato 
do ser. A Filosofia e a Educação podem acontecer como eventos desmistificadores das formulações enganosas e equivocadas dos humanismos que não conseguiram evitar o extermínio de vidas e a perda do sentido do humano. As proposições de Levinas podem ajudar a educadores e educandos a perceber que o sentido do sentido não é uma ideia, um conceito, uma teoria abstrata, a humanidade do humano.

\section{Proposições para a filosofia da alteridade e a educação}

O filósofo franco-lituano, Emmanuel Levinas, surgiu no cenário da filosofia no começo do século XX. A sua vida e sua filosofia desenvolveram-se numa circunstância histórica marcada por fatos terríveis como as duas guerras mundiais e o consequente extermínio dos judeus na Europa. $O$ seu pensamento, apesar de não ser uma reação exclusiva à voracidade e ao horror desses acontecimentos, faz eco desse horror vivenciado por muitos seres humanos inocentes. Os seus textos, produzidos em circunstâncias diversas, exprimem, de forma viva, a força desses acontecimentos como uma espécie de invocação ao pensamento a prestar contas à realidade.

É notório o esforço que Levinas fez para sugerir o reconhecimento do vínculo indissociável que existe entre o pensamento e a existência histórica. E a partir daí, abrir as possibilidades do pensar como um interdito ao horror da violência e do assassinato dos homens.

A atividade reflexiva e as operações do pensamento ficam colocadas à prova pela forma como se articulam com os acontecimentos decisivos da vida histórica. Impõe-se ao pensamento, pensar a si mesmo de modo rigoroso, a ponto de não se deixar usar a serviço da dinâmica do mal e da indolor indiferença para com a morte dos outros. É louvável a postura de Levinas quando se refere aos fatos que têm significação da gravidade. Ele não tangencia os fatos nem os dilui numa 
generalidade, que por vezes amortece o seu impacto de constrangimento. Ele prefere ir direto aos acontecimentos na sua singularidade precisa,

fala-nos, de modo mais preciso possível, da singularidade dos acontecimentos, desvelando-nos nitidamente o aspecto fundamental de cada um em relação à destruição dos judeus na Europa, assim como à criação do Estado de Israel, e na escolha de cada um de nós, à morte, ao nascimento, à carícia e ao traumatismo.(SEBAH, 2009, p. 37)

Pensar apegando-se sempre aos acontecimentos, mesmo que na sua dureza, não é somente uma postura metodológica herdada da fenomenologia husserliana, mas uma exigência radical do proceder e produzir a própria racionalidade. Filosofar significou para Levinas estar permanentemente desperto e vigilante perante os fatos em sua radicalidade. São eles que se impõem como desafios ao próprio movimento do pensar. É deles que brotam as significações moventes do percurso do pensamento na sua busca de sentidos.

Assombrar-se com o que acontece apareceu a ele como provação originária ao filosofar original. Invocar os fatos, "ir às coisas mesmas", é um modo de escapar de um tipo de razão que procede na e a partir da formalidade conceitual abstrata, ou de seus conteúdos reais nas suas próprias criações. Por outro lado, é uma forma de evitar um tipo de má consciência que se apoderou da Europa Moderna ao assumir a razão como única redentora e emancipadora do homem mediante o saber. Talvez por não atentar suficientemente para os fatos, discerni-los avaliativamente, a razão tenha tido que suportar o tremor e o terror do que efetivamente aconteceu na Europa na primeira metade do século XX.

Levinas constata que é chegada a "hora dos balanços". É convicto da vigência da

má consciência no fím de milênios da gloriosa Razão, da Razão Triunfante do Saber; mas também no fim de milênios de lutas fratricidas políticas mas sangrentas, do imperialismo 
tomado como universalidade, de desprezo humano e de exploração e, até este século de duas guerras mundiais, da opressão, dos genocídios, do holocausto, do terrorismo, do desemprego, da miséria sempre incessante do Terceiro Mundo, das cruéis doutrinas do fascismo e do nacional-socialismo e até o supremo paradoxo em que a defesa da pessoa se inverteu em stalinismo.(LEVINAS, 1997, p. 242)

Pode-se perguntar: não são esses acontecimentos suficientemente graves para passarem despercebidos, para uma razão que se compreendeu iluminadora das trevas? Não são eles, na sua densidade, acusadores de uma razão indiferente ao real? Não foram eles responsáveis pelo extermínio vitimador de milhões de inocentes? Não são eles também que se constituem como instância crítica da racionalidade centrada em si mesma? Por conseguinte, não são eles também que apontam para a urgência de se perceber a "hora de se fazer os balanços" e decidir sobre a continuidade ou interdição desses fatos tão acusadores da fragilidade de uma forma de racionalidade que se pretendeu luz e guardiã dos homens no Ocidente?

Levinas nos propõe rever as fontes, os meios e as modalidades do pensar e do agir e, a partir dessa revisão, fazer uma tomada de decisão importante. Decidir sobre a permanência de existir no tempo e no espaço histórico ou fingir que a temporalidade se inscreve na dimensão do mistério indiscernível e, por isso, pode ser ignorada sem acarretar transtornos ao existir das grandes proposições das ciências e dos notáveis princípios éticos. Talvez seja legítimo dizer que os acontecimentos elaborados pela ciência e os nobres preceitos da moralidade que defendem um humanismo, só foram eficazes quando se tornaram meios e ferramentas a serviço da cultura, que permite à política operar como exímia fabricante de fazer vítimas, perfeitamente justificadas e quantificadas racionalmente.

As considerações, expostas acima, podem ser assumidas como razões suficientes para justificar o esforço de Levinas, em propor uma nova orientação para o fazer teórico, a ação moral e 
as práticas educacionais. A orientação se encaminha na perspectiva de superação e transformação das estruturas e formas de operações do pensamento constituído desde os gregos na tradição ocidental.

Em primeiro lugar, Levinas propõe a transformação do pensamento que visa ao saber. Na pretensão de saber, o pensamento organiza-se num modelo de relação bipolar. De um lado fica o sujeito que deseja o conhecimento e de outro o objeto que pode ser conhecido. Na dualidade sujeito-objeto, o sujeito tem um privilégio por ser o polo ativo, o que atua sobre o objeto. $\mathrm{Na}$ atuação do sujeito, toda a exterioridade é reduzida à interioridade da consciência.

A relação de saber é uma forma de relação do mesmo com o outro, em que o outro é reduzido ao mesmo, tolhido de sua condição de outro, de alteridade. Nessa modalidade de relação, o que é compreendido como transcendência não passa de uma simples ilusão, uma projeção do pensamento ou então uma realidade que sugira a experiência e suas condições possíveis e, por isso, não pode ter legitimidade para a especulação fillosófica. $\mathrm{Na}$ relação sujeito-objeto, acontece necessariamente a objetivação do outro e sua redução ao mesmo identificador e nivelador de toda diferença. O outro é radicalmente diferente em relação aos objetos do mundo, em relação a mim e aos outros $\mathrm{e}$, portanto, não pode ser objetificado, a não ser numa envergadura violenta. A forma de relação bipolar, sujeito-objeto, não considera o existir humano e as relações inter-humanas com densidades impactantes em termos práticos e éticos. A mediação entre os polos acontece por um termo neutro que não apreende as individualidades dos humanos na sua singularidade, mas as encaixa numa generalidade que não se particulariza no interior da consciência permanente que identifica tudo e a si mesma como mesmidade.

Levinas propõe a superação da primazia do saber, porque considera o outro, a alteridade inadequada a uma investidura gnosiológica. É muito interessante notarmos que um pensador 
da estatura de Gadamer, tecendo a diferença entre a ciência grega e a moderna, menciona Levinas exatamente no que tange ao saber:

Se o saber de Levinas é contraposto à transcendência do outro, ele estabelece um limite para o tema que é completamente diverso daquele que veio à tona no interior da história da ciência no ocidente. Sim, parece-me que a transcendência desempenhou um papel determinante justamente nas formações e transformações da ciência que se realizaram na história ocidental e não representa apenas um 'para além de toda a ciência' e de sua 'imanência'. O 'totalmente outro' de Deus, o outro dos outros, dos próximos, aquele de natureza fechada em si - todos eles não se entregam à responsabilidade de nosso saber. (GADAMER, 2007, p.10)

Em segundo lugar, ele sugere a transformação da concepção de Subjetividade Transcendental. A linguagem da modernidade inclui e assume um discurso ético. São muitas as modalidades de teorias e orientações morais. Essas orientações apresentam-se com a pretensão de validade universal. Em resumo, pode-se dizer que a razão moderna fala da ética a partir de teorias racionalmente impecáveis, com extremo rigor lógico e objetivo. A assunção da filosofia em filosofia transcendental acontece por sobre as experiências singulares e se conforma como os esquemas abstratos, "o eu se torna sujeito transcendental, move-se de acordo com os postulados formais da razão, nas operações seguem a generalidade ou objetividade." (PIVATTO, 2001, p. 82)

Até mesmo a pretensão de mover o conceito à realidade processa-se envolta da abstração. $\mathrm{O}$ abstrato, assim, pretende fundar e assegurar instituições que garantam a efetividade e universalidade da ética. Na verdade essas pretensões ficaram apenas em projetos abstratos. O que de fato aconteceu foi a ruína do Humanismo, a perda de sentido das instituições e a deteriorização das relações intersubjetivas que Levinas reconhece ter acontecido, "na política e na técnica que convergem na negação dos projetos que a conduzem". 
(LEVINAS, 1993, p. 67)

Mediante a não realização desses projetos, e porque não dizer do seu fracasso, Levinas propôs romper com a subjetividade transcendental, enquanto fria maneira de racionalidade, e substituí-la pela atividade do humano que se apresenta e faz apelos em carne e osso. Ou seja, sugere a concretude da relação entre os homens com base sustentadora para se pensar a ética. Temos, dessa maneira, uma nova concepção de subjetividade, nas palavras de Pivatto, "cuja órbita e ótica transcendem o ser e a transcendentalidade".

A toda perspectiva de compreensão de Husserl de pensar a consciência estruturada intencionalmente e com a possibilidade de constituir a objetividade dos objetos e toda a realidade do sentido, Levinas vai muito respeitosamente manifestar o seu desacordo e esboçar uma reação crítica.

Em primeiro lugar, discorda da função ativa do eu, sobretudo quando esta atividade se apresenta como a sua essência. Para ele, a "essencialidade" do eu enquanto subjetividade é ser ética. Essa é a sua função primordial, o seu estatuto identificador é, até mesmo, o seu sentido fundamental. $\mathrm{O}$ eu não é primeiramente sujeito cognoscente numa relação de conhecimento, mas polo de uma relação aberta com o outro. A tentativa de reduzir o outro à condição de objeto de conhecimento fracassa, pois ele não se deixa objetivar nem representar numa relação teórica. Levinas não aceita que o outro seja constituído pelo eu. Entre o eu e o outro há uma separação que permite ao outro manter-se numa dimensão de autonomia como quem assume uma condição de transcendência. Em segundo lugar, discorda que o eu seja doador de sentido. Assegura que o outro tem o sentido em si mesmo e que, originalmente, aparece como "auto-significante". E porque tem o sentido em si mesmo pode ensiná-lo. $\mathrm{O}$ eu é discípulo do outro, que é mestre. Em terceiro lugar, não aceita a estrutura intencional da consciência, que reduz tudo à interioridade. Para ele o outro fica sempre no exterior. É transcendente. A 
exterioridade é a forma adequada para manter a sua condição de separado, fora do circuito da intencionalidade. Por isso, não se iguala. Mesmo a relação que se estabelece tem que se manter nesta forma de radical assimetria. $O$ outro não se iguala simetricamente. Ele tem uma dimensão de altura que lhe permiter-se manter outro como ente diferente.

Por causa de sua maneira de ser, é que ele provoca no eu uma atração, um chamamento, uma solicitação. Aos apelos do outro o eu tem que dar uma resposta. Ele não tem a alternativa de ficar indiferente diante dos apelos do outro. Não porque não possa ficar indiferente, mas por causa da radicalidade dos apelos do outro. Exigência que se apresenta como imperativo que não pode ser recusado.

Ao contrário do que afirmou Husserl, Levinas fez derivar o sentido de uma outra forma de relação que não a teórica. Agora o sentido tem que ser buscado numa dimensão que se apresenta na experiência ética e não mais na trama da intencionalidade. A consciência de que em Husserl tem uma função ativa de constituição de sentido e objetividade, é vista por Levinas como abertura para o acolhimento do outro. $\mathrm{O}$ eu não é mais o ponto de iniciativa, mas o polo de recepção da provocação e lugar da possibilidade da resposta. É, portanto, na possibilidade de uma relação com o outro que o eu se constitui. É também a partir dele mesmo que deve ser pensado, fora de qualquer horizonte definido pela compreensão.

Uma nova forma de pensamento em que seja possível destituir o privilégio da subjetividade e da intenção cognitiva e instituir o primado ético, onde o outro aparece como alguém com quem é possível estabelecer uma relação, que possa se fazer próximo, encará-lo num frente a frente. Assim, o outro se apresenta como alguém que tem a sua própria identidade e não a identidade construída pelo eu cognitivo. Agora ele aparece como um convite ao estabelecimento de uma relação social e não como um objeto que pode ser feito tema e, portanto, objeto.

A objetividade possível da relação com o outro é o próprio 
estar presente, fazer frente ao outro ou, por assim dizer, a experiência da relação que se concretiza no encontro com o outro. Essa sim, é uma objetividade real, porque passa pela concretude temporal do acontecer. Não é uma objetividade formal, instituída por um pensamento que cria objetos de conteúdos lógicos e realidades que apenas existem como formas abstratas.

O sentido ético que advém dessa nova forma de pensamento tem a excelência de ser um sentido que brota de uma concretude experiencial que se efetiva temporalmente. É uma objetividade mais objetiva do que a objetividade pleiteada por Husserl. Pois se trata de uma objetividade que não é objetividade de um objeto, mas de outrem que não se objetiva, que se oferece numa relação ilimitada.

Em terceiro lugar, ele propõe a transformação dos conceitos da Filosofia. Aqui se coloca em evidência o método do fazer filosófico. O tradicional método transcendental processa-se com o fim de alcançar um fundamento ou encontrar uma justificativa para uma tese ou idéia postulada, pretende-se encontrar uma condição que a torne possível, mediante um enlaçamento lógico coerente até se chegar a uma evidência conseqüente. Nessa ação do pensamento, que vem da intuição moderna cartesiana, privilegia-se o ordenamento do ser, a apropriação do objeto, a compreensão como saber e a correlação de sujeito cognoscente e objeto cognoscível.

Nesse privilégio, desaparece o espaço da alteridade. A sua descoberta da fenomenologia lhe permite uma nova possibilidade de desenvolver os conceitos, "passar de uma ideia a outra". Isso lhe permite enxergar fenômenos que ficam recolhidos na intimidade da consciência, e que expõem "o sentido da objetividade ou do ser". Daí se explicita a sua atenção a dimensões tão simples do existir como "o cansaço, a vigília, o tédio e o peso do existir". $\mathrm{Na}$ base dessas realidades, que não são percebidas pelo método transcendental, ele percebe as dimensões do humano que podem ser explicitadas na 
linguagem. $\mathrm{O}$ que fica escondido em segredo é a relação entre pessoas que constituem para ele "a textura da inteligibilidade última e a instauração do sentido do humano", não percebido por outras perspectivas conceituais. A nova maneira de desenvolver os conceitos capta a própria inteligibilidade e o sentido do existir do humano, fora deles. Isto não significa irracionalidade, mas racionalidade outra.

Em quarto lugar, propõe a transformação da ideia de que a ética é apenas um aspecto da filosofia. É visível desde os primórdios da filosofia grega a vigência de teorizações da vida moral. Nenhum grande pensador conseguiu organizar o seu sistema filosófico prescindindo da moralidade e da ética. No percurso da filosofia ocidental, grandes sistemas foram erigidos na intenção de orientar as ações dos homens nos níveis pessoal e coletivo. No entanto, todos esses sistemas entraram em crise no seio das configurações culturais no Ocidente. O que foi proposto como orientação e afirmação dos humanos acabou sendo motivo de desagregação, conflito e esquecimento deles. Levinas tem consciência dos limites dos propósitos éticos, mas não prescinde de sua vigência. Sugere transformar as âncoras promovidas pela tradição grega afirmadas no ser, no saber e no poder. Acolhe como inspiração-base a tradição semita que propõe a moralidade como fundamento da existência e das relações sociais.

Ele pensa ser possível acrescentar a essa tradição Ocidental instituições sublimes, não suficientemente levadas a sério, como a ideia de Platão bem além do ser, a ideia cartesiana de infinito e o imperativo categórico kantiano. A partir dessas idéias, ele propõe a relação com o outro como superioridade absoluta em relação ao ser e ao conhecimento. A relação com o outro é constituinte fundamental do movimento que pode levar até a transcendência do bem que nos pode ser apresentado pelo rosto do outro homem na experiência ética. É aqui o âmbito próprio, no qual é permitido pensar a alteridade que "não é apenas uma qualidade do outro, é sua realidade, sua instância, a 
verdade do seu ser".

Finalmente, Levinas propõe a pedagogia centrada no rosto, na justiça e aberta ao terceiro. Em Totalidade e Infinito pode-se perceber a nítida relação entre o rosto e a justiça. Quando Levinas se ocupa em apresentar sua reflexão sobre a relação implicativa de "outrem e os outros", desenvolve um intrigante entrelaçamento de conceitos que podem ser compreendidos na perspectiva do alargamento do alcance da ética. De início, ele delimita o horizonte de compreensão do rosto, enfatizando a necessidade de compreendê-lo como diferente de um fenômeno que pode ser dado à compreensão inteligível e possuído por um sujeito cognoscente. Para ele "o que se dá, o que se toma, reduz-se ao fenômeno, descoberto e oferecido à captação, arrastando uma existência que se suspende na posse" (LEVINAS, 1980, p.190).

A posse caracteriza o possuído como objeto particular, determinado como realidade dada. $O$ rosto não tem uma espessura de uma fenomenalidade determinada em realidade objetiva. A sua apresentação exprime um outro modo de ser e existir. Levinas afirma que "a apresentação do rosto põe-me em relação com o ser. $\mathrm{O}$ existir do ser-irredutível à fenomenalidade, compreendida como realidade sem realidade" (LEVINAS, 1980, p. 190).

A efetivação da relação com o rosto dá-se na disposição de oferecer a resposta que ele exige, ou seja, "efetiva-se na inadiável urgência com que ele exige uma resposta" (LEVINAS,1980, p.190). Na modalidade da resposta ou nas condições a ela dadas pode-se perceber o alargamento no significado da relação ente outrem e outros. A resposta dada ao rosto difere daquela exigida por um dado objetivo. Ela tem que ultrapassar o limite da objetividade das coisas e o âmbito do nós. Quando Levinas diz que a resposta não pode ficar entre nós, quer sugerir pensarmos nas possibilidades das apropriações particulares ou mesmo das ações de ressonância curta.

Ora, o âmbito intersubjetivo, familiar ou mesmo 
comunitário pode ser vivenciado como espaço privado. As vivências éticas podem ocorrer nessas dimensões como instâncias individualizadas. Os sujeitos da relação intersubjetiva podem acordar circunstâncias que lhe sejam favoráveis, mas não favorecem outrem. É aqui que se reclama o ultrapassamento do particular nós e o implemento do universal da ordem pública: "tudo que se passa aqui entre nós diz respeito a toda gente, o rosto que o observa coloca-se em pleno dia da ordem pública". (LEVINAS, 1980, p. 190).

A ordem pública tem o extraordinário poder de pôr em questão determinadas preferências que muito bem satisfazem a interesses individualizados. Manter-se na afirmação das opções que convém à relação eu-tu, mesmo que sejam convicções de um amor verdadeiro, não é suficiente para garantir a resposta à altura das exigências do rosto. $\mathrm{O}$ rosto, que pode fazer-se presente como linguagem, evoca a presença do terceiro, que só nos atinge através de outrem. A entrada do terceiro na relação abre o espaço público e visibiliza a justiça: "o terceiro observanos nos olhos de outrem - a linguagem é justiça." (LEVINAS, 1980, p. 190).

$\mathrm{O}$ acontecimento da linguagem verifica-se como um evento negador da privacidade ou da posse individualizada do mundo. Nessa perspectiva, pode-se entender que a forma como o rosto se faz presença provoca a instauração da humanidade: "a epifania do rosto como rosto abre a humanidade" (LEVINAS, 1980, p. 190). É muito significativo perceber-se a profundidade humana que o rosto nos revela. Ele expõe-nos a humanidade no seu estado de indigência e penúria, apelando para o nosso poder: "o rosto em sua nudez apresenta-me a penúria do pobre e do estrangeiro" (LEVINAS, 1980, p. 190).

Levinas compreende que o pobre e o estrangeiro apresentam-se como iguais na pobreza e que "sua igualdade na pobreza essencial consiste em referir-se ao terceiro." (LEVINAS, 1980, p. 191). O terceiro aparece para o encontro fazendo apelo ao serviço. Enquanto apela a partir de sua própria 
indigência, também profere uma ordem. Ordem que manda mandar, por assim dizer. A convocação do terceiro a juntar-se a ele e a mandar apresenta-se como ordem vinda de uma fonte de poder que não domina, nem manda dominar. Trata-se de uma ordem vinda de quem tem sabedoria e pode ensinar como mestre e reconhece no seu mandado também o estatuto do mestre no exercício do serviço. Diz Levinas: "junta-se a mim. Mas junta-me a ele para servir, ordena-me como Mestre. Ordem que só pode dizer-me respeito na medida em que eu próprio sou mestre, ordem, por conseguinte, que me ordena que mande" (LEVINAS, 1980, p. 191).

No exposto fica patente a força e importância do terceiro. Ele traz consigo uma convocação para juntar-se a ele e, ao mesmo tempo, um mandato, uma ordem. Instaura uma relação triádica. Aquele que recebe uma ordem, a recebe de um outro. E imediatamente é ordenado para mandar outrem. Há uma espécie de movimento que suscita também um dinamismo de abertura do receber e dar. Aquele que recebe ordens também é solicitado a dá-las. A relação entre três, incumbe a cada um assumir um compromisso que envolve necessariamente os outros. Entra em cena aqui toda a dimensão da responsabilidade e da justiça.

É nesta dimensão que a ideia de autonomia e de liberdade é posta em questão. Um eu não se afirma nem se define com referência a si mesmo ou simplesmente a um outro. A sua possível afirmação está condicionada à sua possibilidade de transcender não só o egoísmo, mas também o nós. A responsabilidade que ele foi chamado a assumir, o obriga a comprometer-se com tudo o que concerne à humanidade. $\mathrm{O}$ agente da responsabilidade é convocado a duplicar não somente o seu discurso, mas também o seu empenho para atender ao chamado do terceiro, presente no rosto do outro. Nessa trama entre os três, o eu pode pronunciar a palavra profética que responde à manifestação do rosto enquanto prova viva da presença do terceiro que lhe apresenta toda humanidade. Nas palavras de Levinas,“... momento irredutível do discurso 
suscitado essencialmente pela relação do rosto enquanto ele atesta a presença do terceiro, de toda humanidade, nos olhos que me observam" (LEVINAS, 1980, p. 191).

A revelação do rosto que faz efetiva a presença do terceiro evoca também as possibilidades dos discursos acontecerem em sintonia com a ética da justiça ou com outras atitudes que não são dignas de qualificativos éticos positivos. Em outras palavras, no acontecimento da linguagem pode haver justiça e injustiça. Isso impõe a necessidade fazer algumas distinções ou caracterizar a linguagem que é própria do rosto e aquela que se diferencia por sua qualidade imoral. É nessa ambiguidade, sempre aberta, que o trabalho educativo ganha toda a sua significação. As proposições levinasianas são bem claras. A ação educativa deve estar sempre comprometida com a vivência da justiça, com o acolhimento do rosto e com a linguagem que humaniza o humano.

Considerações finais

A reflexão que realizamos sobre Subjetividade em Levinas nos levou a concluir que, no que concerne às analises do rosto, ele propõe uma nova categoria para a reflexão filosófica e um novo estilo de produzir a própria nacionalidade. Com a noção de Rosto, Levinas se propõe fazer uma descrição da ética destituída das engrenagens da ontologia. O rosto assume uma significação originária que se diferencia radicalmente das categorias formais e do rigor da razão lógica.

A categoria do rosto se constitui na possibilidade de considerar o humano para além das tessituras de inteligibilidades enraizadas apenas no $\operatorname{logos} \mathrm{e}$ nas suas determinações. Abordado dessa maneira, o rosto quando foi considerado na tradição, nunca foi compreendido como algo distinto de um ente objetivo do corpo humano. Determinações bem particulares como: fronte, boca, nariz, olhos, sempre foram consideradas como objetos de análises das ciências do homem.

Vimos que Levinas se contrapôs a essa perspectiva de consideração e propôs uma reflexão sobre o rosto como um 
lócus de revelação profunda do humano, capaz de ser expresso na pessoalidade e na abertura para o outro.

Como acolhedor da diferença do outro e respondente incondicional de suas solicitações, o rosto apresenta a significação mais sublime do humano, que é ser para o outro. Portanto, o rosto exprime o sentido ético do existir humano enquanto possibilidade de construir a sua identidade na aventura da abertura permanente para o outro.

Concluímos também que Levinas compreendeu a subjetividade de modo muito diferente da tradição da filosofia. Aos modelos mais eminentes da subjetividade como o transcendental moderno e o constituinte de Husserl, Levinas contrapôs o modelo da hospitalidade. À subjetividade que se apresentou como atividade teórica e constituidora do sentido da realidade, ele apresentou a alternativa para ela configurar-se como subjetividade aberta ao acolhimento do outro. Desse modo, a subjetividade perdeu a sua função cognitiva e teórica e assumiu a relacionalidade desinteressada para com o outro como o novo âmbito do acontecer do sentido. Nessa perspectiva o eu deixou de ser uma entidade abstrata que tinha a autonomia e se auto proclamou como sujeito e passou a ser polo de uma relação possível com os outros. Assim, a constituição da subjetividade acontece na medida da relação com outro. A verdade e a objetividade possíveis são dados na medida da retidão do encontro com o outro.

Vê-se que, assim como o rosto, a subjetividade foi pensada na perspectiva da ética. Portanto, o sentido ético que brota desse modo de pensar tem a magnitude de originar-se da concretude existencial e temporal. Nesse sentindo a subjetividade ganha uma dimensão de objetividade eminente e privilegiada, pois se trata de uma objetividade que não tem referência de objetos, mas de outrem que se abre na sua infinitude. Para Levinas, é nessa abertura infinita para outrem que a subjetividade ganha o seu estatuto de sentido. Em suma, vimos que a subjetividade plasma-se como instância 
fundamentalmente ética e pode expressar-se no desejo desinteressado pelo outro; na responsabilidade por ele; e tem como medida a desmedida do infinito; na escuta paciente de quem reconhece no falante uma autoridade ensinante; na hospitalidade, como aquele que se alegra pela visitação desarranjadora do visitante inusitado; no encontro face a face com o rosto de outrem que traz uma significação originária e originante de novos sentidos: dizer de aprendizes e ensinantes.

\section{Referências}

GADAMER, Georg. Hermenêutica e a Filosofia Prática. Petrópolis: Vozes, 2007.

LEVINAS, Emmanuel. Totalidade e Infinito. Lisboa: Edições 70, 1980. . Entre Nós. Petópolis: Vozes,1997. Dificil Libertad: y otros ensayos sobre judaísmo. Buenos Aires: Lilmod, 2004.

PIVATTO, Pergentino. Correntes Fundamentais da Ética Contemporânea. Petrópolis: 2001.

SEBAH, François-David . Levinas. São Paulo: Estação Liberdade, 2009. 